\title{
INFLUENCE OF LATE FEEDING IN POST-HATCH CHICKS ON YOLK SAC ABSORPTION, DIGESTIVE SYSTEM DEVELOPMENT AND BROILER PERFORMANCE
}

(Received:21.8.2008)

\author{
By \\ M. Aboud and M. Alrayes \\ Department of Animal Production, Faculty of Agriculture, Damascus University, Syria
}

\begin{abstract}
This study was carried out using (900) broiler chicks of the hybrid (Lohman). The chicks were divided equally into three groups, each in 3 replicates. However, they were different due to the start of feeding in post-hatch, where the feed was given in the control group after 6 hours of hatch, after 24 hours of hatch in the first experimental group and after 48 hours of hatch in the second one and the water was free during post-hatch period for all groups.

The birds were fattened until 42 days, using three types of diets as follows:

-Starter: 1-14 days.

-Grower: 15-35 days.

-Finisher: 36-42 days.

The obtained results showed that:

1-The birds fed 6 hours after hatch showed an advantage in yolk sac absorption and digestive system development.

2-The general performance of birds fed 24 or 48 hours after hatch decreased, where final live weight and feed conversion values decreased and the accumulative mortality rate increased.

3-The birds fed 6 hours after hatch was the best in the slaughter characteristics, and the control birds contained less abdominal fat compared to the first and second groups.

4- The best feed conversion value was in the control group especially at 42 day.

The early feed after hatch in the resulted best performance for broiler.
\end{abstract}

Key words: broiler performance, digestive system development, yolk sac absorption.

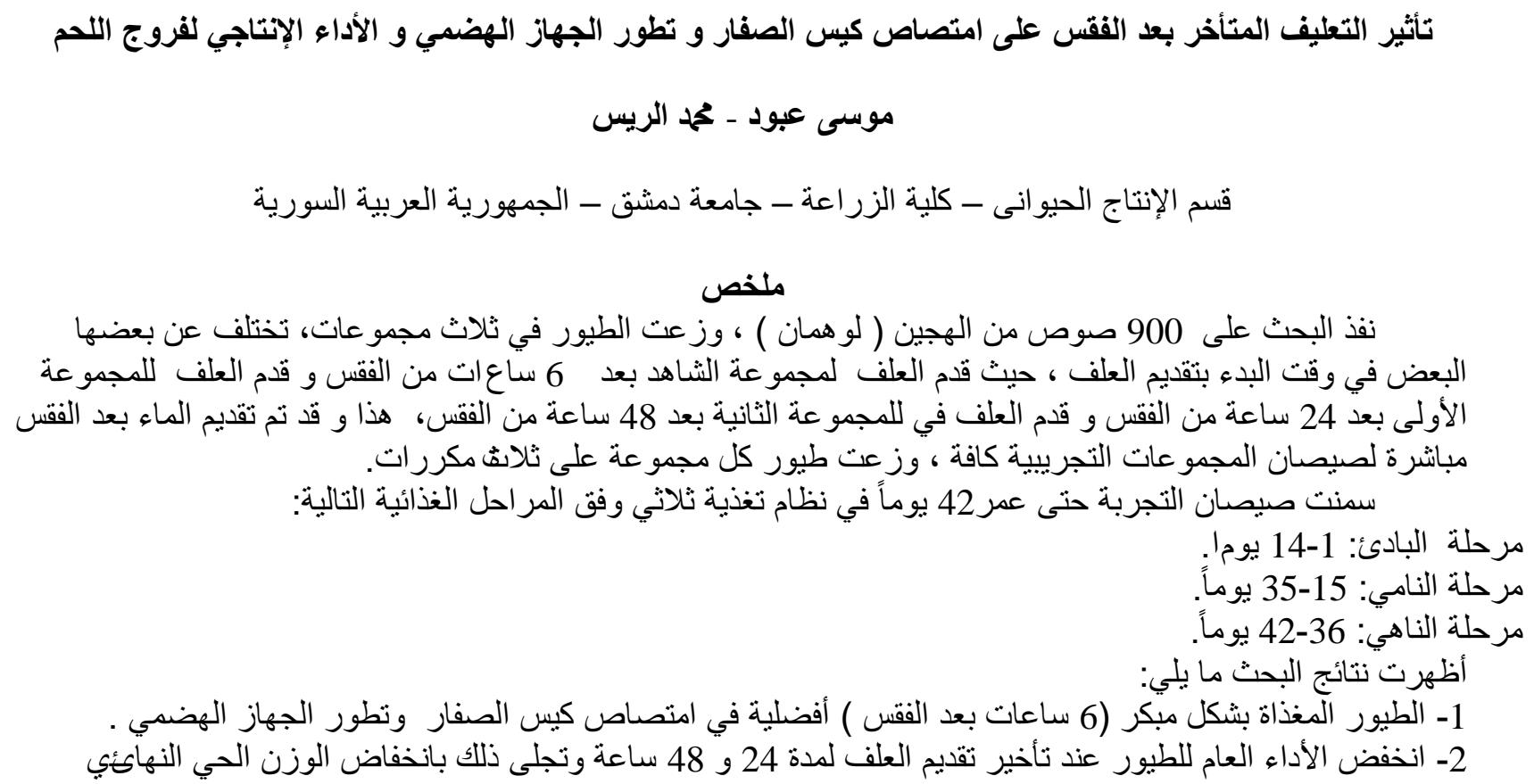


و كفاءة تحويل العلف و زيادة نسب النفوق التر اكمية.

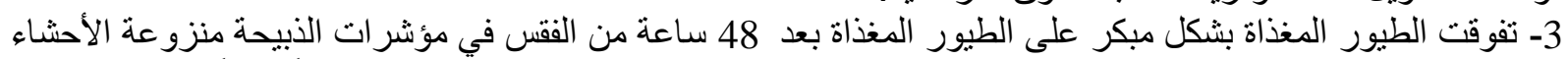

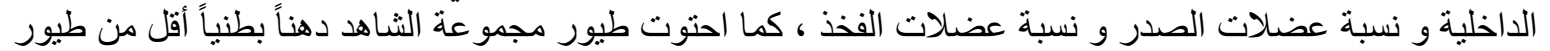

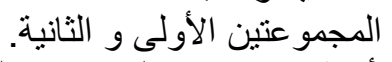
4-أعطت مجمو عة الثناهد معامل تحويل غذائي أفضل عن باقي المجاميع خاصة الثئ في نهاية فترة التسمين.

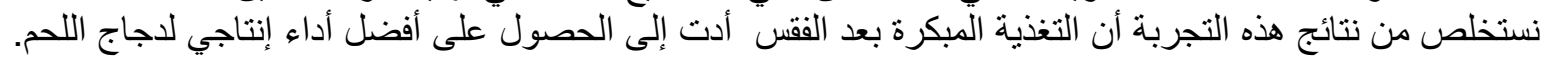

يستطيع الصوص الاستفادة من المتبقي من كبس (لفيس

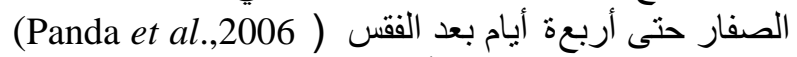
حيث امتصاص العناصر الأساسية النادرة و المضام المضادات

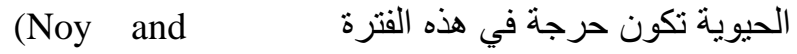
(Wertlecki,2006) و Sklan, 1999b)

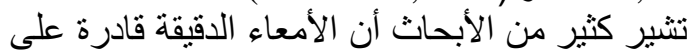

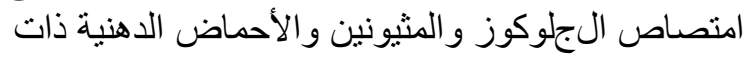

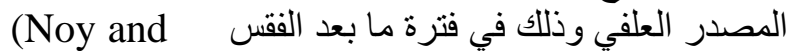
و وأكد (Noy and Sklan, 2001 1998) تغذية الصيصان بخلطات علفية منخفضة في محتو اها من المن الهن

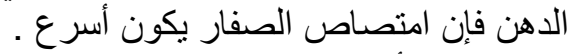

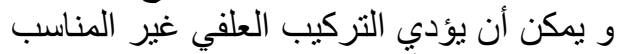

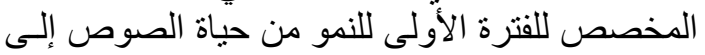

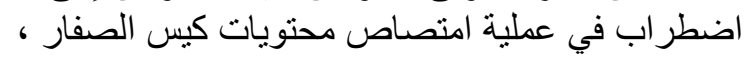

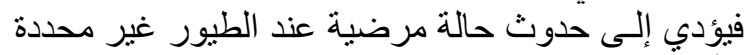
الأعر اض (Wertelecki and Jamroz,2000) . يحرض العلف المقدم في فترة ما بعد الفقس على إفراز

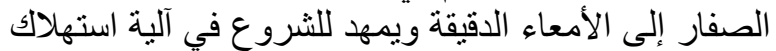

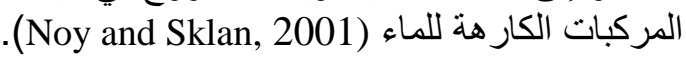
يستمر وزن الصوص باء بالانخفاض في فترة ما بعد

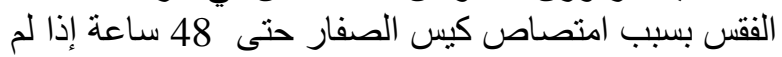

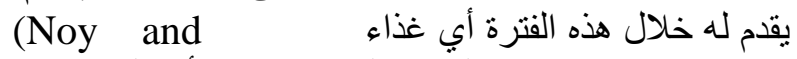

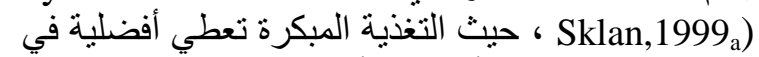

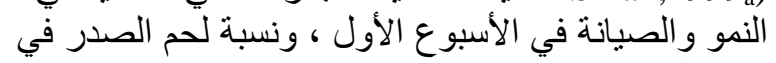

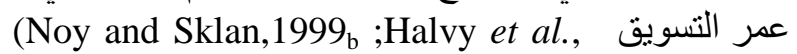
(2000 و تشير الدراسات الحديثة إلى أن الصفار المتنقي

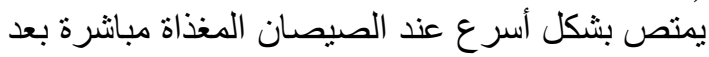

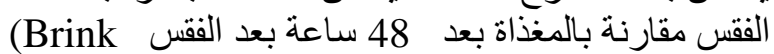
(and Rhee.,2007)

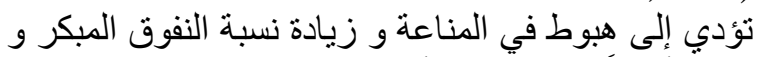

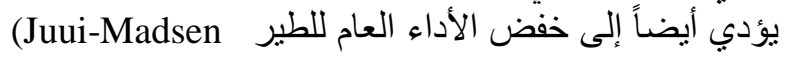
.et al.,2004)

في الأحو ال العادية لا يقدم الغذاء و الماء للصيصان في

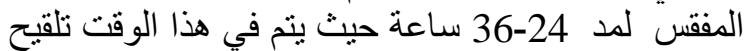

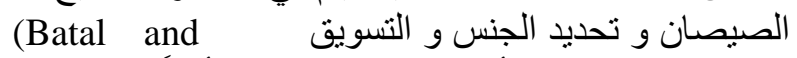

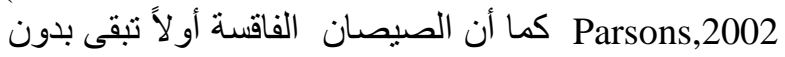
غذاء و لا ماء حنى انتهاء فقس كامل بيض الته التفريخ في الني

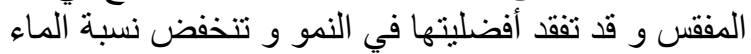

الكامن في أنسجتها (Tweed,2005)

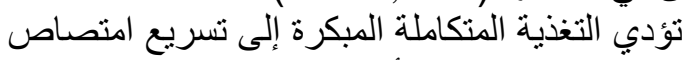

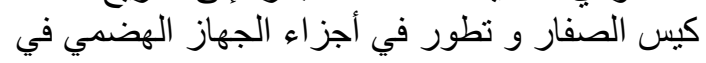

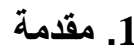

بسعى المربون لاستغلال سرعة النمو النسبية مقاية

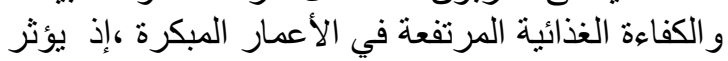
مستوى التغذية في هذه المرحلة العمرية على التئية التطور

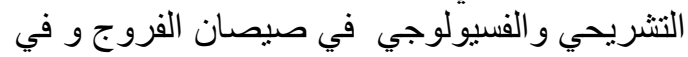

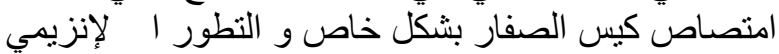
للجهاز الهضمي و البنكرياس وكذلك على النى نمو الجهاز

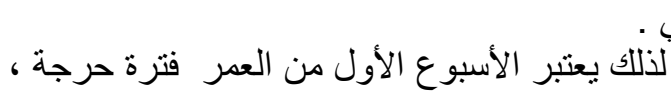
بل أهم فترة في نمو الجسم ، لإسبرع حيث نوه العديد العبر من الباحثين

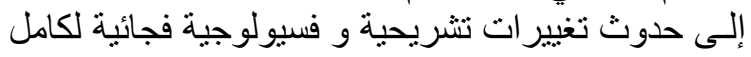

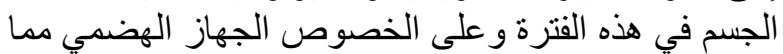

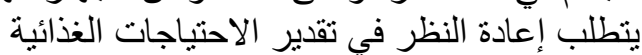

للصيصان في هذه الفترة الحرجة من الحئرة الحياة (Grela,1998) و و (Majewska et al., 2000) يعتبر كيس الصفار في هذه الفترة بالنسبة للصيصان مصدراً مبكر أ للمركبات الغذائية التي تساعد على النى النمو و

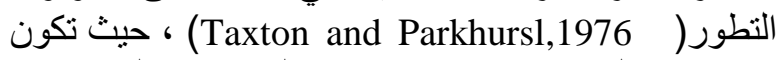
نسبة كيس الصفار 17\% 17 من وزن الجسم عند الفقس ، و

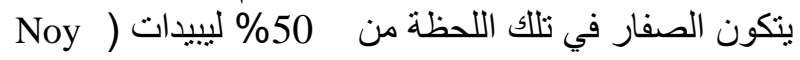
تنتقل مكونات الصفار إلى الأمعاء الدقيقة عبر قناة

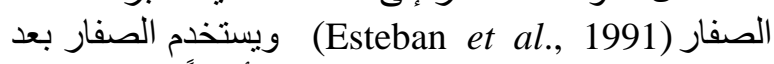
الفقس مبانرة في الاحتياجات الحافظة وأيضاً في نمو الهو الجهاز الهضمي بينما تستخدم طاقة العلف في النمان في النمو

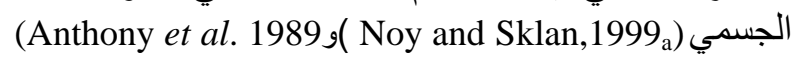
و لذاللك تؤدي التغذية الصحيحة في هذه الفترة العمرية من ون

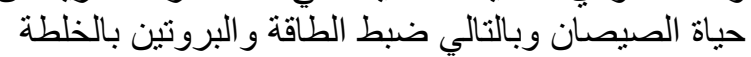

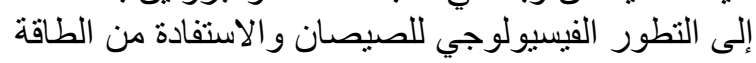

الور اثثية في فترة الرعاية التالية (Jamroz,2000)

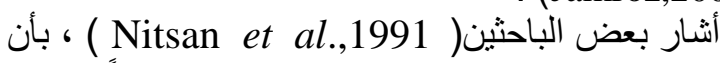

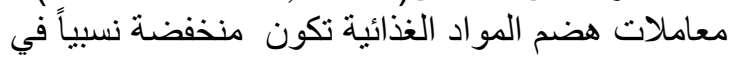

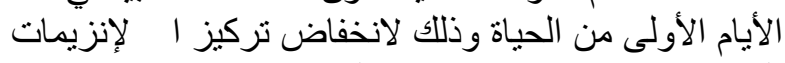

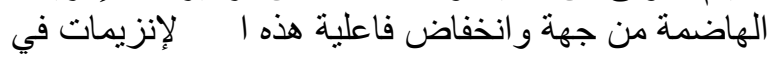

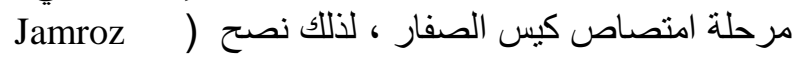

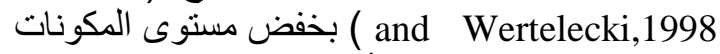

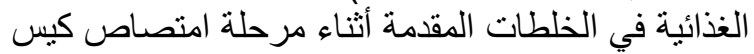

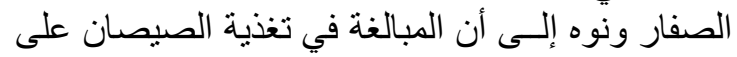

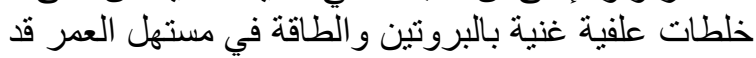

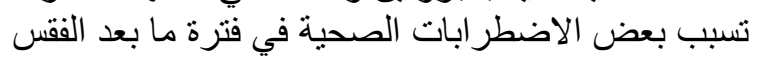
وبالتالي ارتفاع نسبة النفوق. 
حصنت الطيور ضد الأمراض باللقاحات اللازمة وفي المواعيد المبينة أدناه:

\begin{tabular}{|c|c|c|}
\hline طريقة & اسم اللقاح & العمر /يوم \\
\hline بماء الشرب & التهاب القصبات + & 6 \\
\hline بماء الشرب & جمبورو & 12 \\
\hline بماء الثرب & نيو كاسل & 14 \\
\hline بماء الثرب & جمبورو & 23 \\
\hline بماء الشرب & نيو كاسل & 35 \\
\hline
\end{tabular}

جدول (1) المواد العلفية فى تكوين الخلطات المغدى عليها

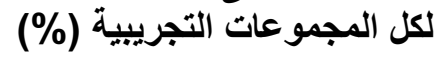

\begin{tabular}{|c|c|c|c|}
\hline الثالثة & الثيانية & الأولى يومل & \multirow{2}{*}{ المادة العلفية } \\
\hline $42-36$ & $35-15$ & $14-1$ & \\
\hline 74 & 69 & 60.2 & ذرة صفراء \\
\hline 22 & 27 & 35.8 & كسبة فول صويا 44\% \\
\hline 2.2 & 2.2 & 2.2 & فوسفات ثثائي الكالسيوم \\
\hline 1 & 1 & 1 & مسحوق حجر كلسي \\
\hline 0.1 & 0.1 & 0.1 & مخلوط فيتامين فروجa \\
\hline 0.1 & 0.1 & 0.1 & مخلوط معادن نادرة \\
\hline 0.1 & 0.1 & 0.1 & كلوريد الكولين \\
\hline 0.1 & 0.1 & 0.1 & مثيونين حر \\
\hline 0.4 & 0.4 & 0.4 & ملح طعام \\
\hline 100 & 100 & 100 & الإجمالي \\
\hline
\end{tabular}

a

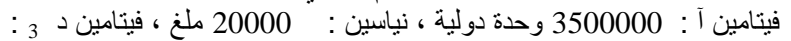

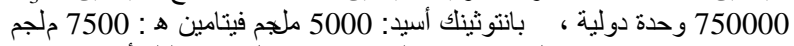

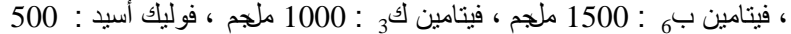

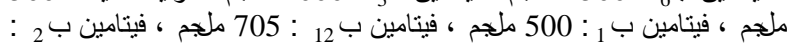

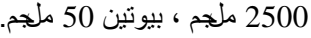
b : مكونات مخلوط المعادن النادرة: كل 1 كلجم يحتوي:

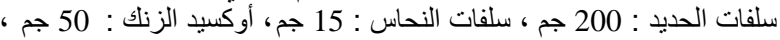

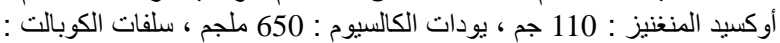
500 ملجم ، سيلينات الصوديوم : 300 جم.

المؤشرات المدروسة وطريقة تحديدها:

1.2. طريقة حساب نسبة امتصاص كيس الصفار نسبة امتصاص كيس الصفار خلال المرحلة=

وزن كيس الصفار في بداية المرحلة ـ وزن كيس الصفار في نهاية المرحلة $100 \mathrm{X}$

وزن كيس الصفار في باية المرحلة
الأسبوع الأول من العمر، كما تؤدي إلى زيادة وزن

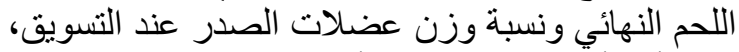

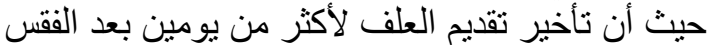

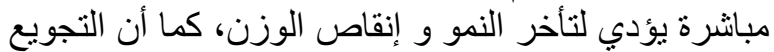

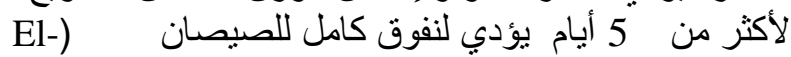
، (Husseiny et al., 2008 و تعطي التغذية المبكرة أفضلية في الزيادة الوزنية،

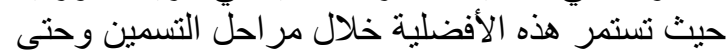
مو عد التنسيق(Henderson et al.,2008). تهدف هذه الدراسة إلى تحديد تأثير تأخير تقديم العلف

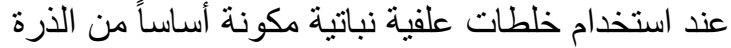

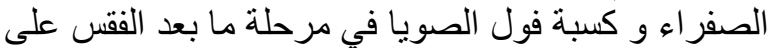

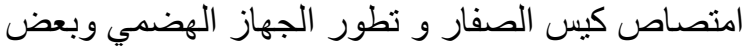
المؤشرات الإنتاجية عند طيور الفروج.

\section{2. المواد و طرق البحث}

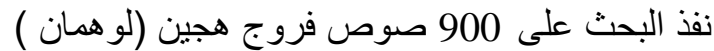
في مدجنة خرابو التابعة لكلية الزر اعة في جامعة دمثنق

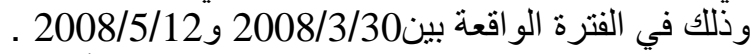

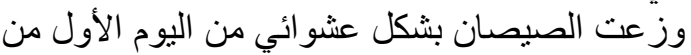

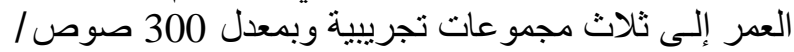

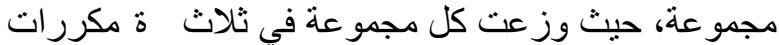
تضمن كل مكرر100 صوص.

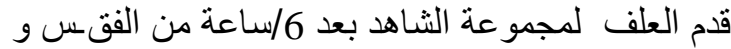

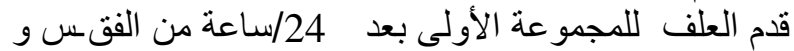

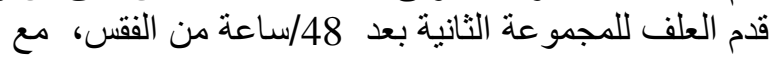

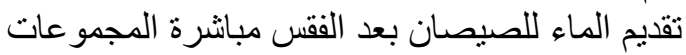
التجريبية كافة.

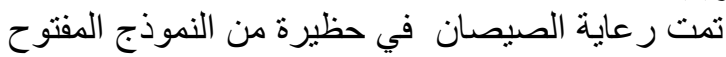

، مقسمة إلى قطاعات بو اسطة حو اجز بيتونية، مساحة

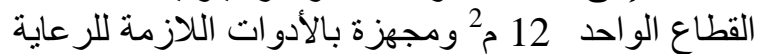
وكانت ظروف الإيو اء و احدة لجميع الطيور في التجربة الطية.

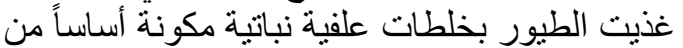
الذرة وكسبة فول الصويا جدول ( 1 ) ) ، أما محتوى هذه فئه

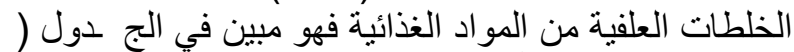

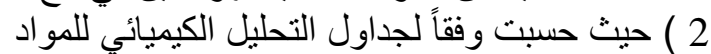
العلفية الموجودة في المراجع العلمية (الرباط

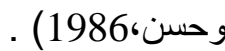
تم في عمر يوم واحد و عمر يومين وسبعة أيام تشريح 9 صوص من كل مجمو عة وبشكل عشو ائي،حيث أخد أخذ من

كل مكرر 3 صيصان، وتم تحديد المؤشر ات التالية : وزئة

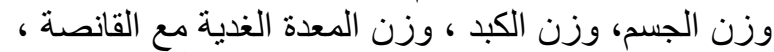

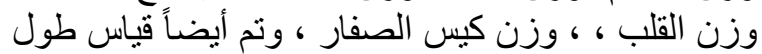

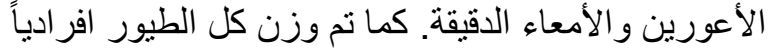
في نهاية كل أسبوع وحتى عمر 42 يوماً. 
المتوسط العام للمجموعة ،وتم ذبح الطيور بعد تجويعها لمدة

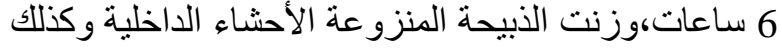

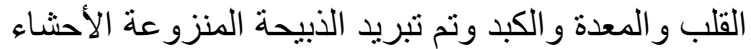

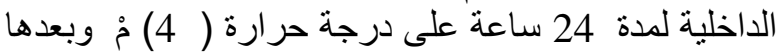
شرحت الذبيحة وحدد بها وزن عضلات الصات الصدر و عضلات الفخذ وتحت الفخذ.

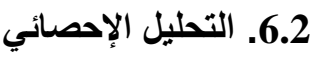
خضعت النتائج للتحليل الإحصائي ونم استخدم البرنامج الإحصائي SPSS المعنوية بين المجمو عات التجريبية على مسنوى كما حسبت الفروق المعنوية بين النسب المئوية (P<0.05)

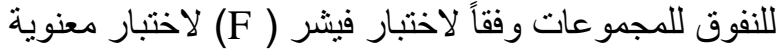
الفروق بين النسب المئوية.

\section{3. النتائج و المناقتشة}

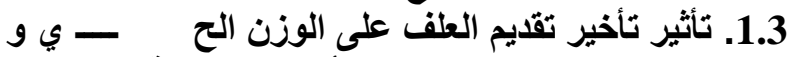

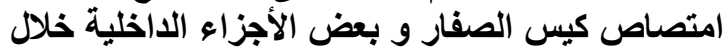

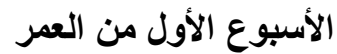

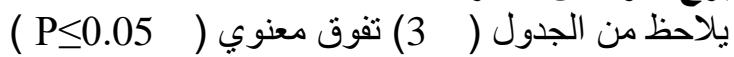

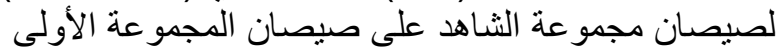

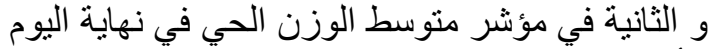

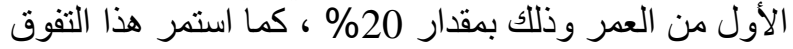

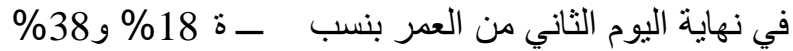

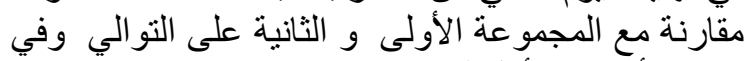

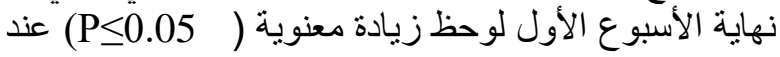
طيور مجمو عة الثاهد في متوسط الوزن الأن الحي وبنسبة 16 و 26\% مقارنة مع المجمو عتين الأولى و الثنانية على الثى

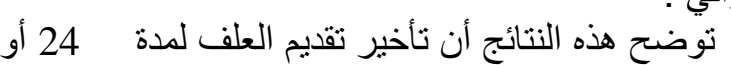

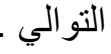

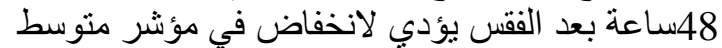

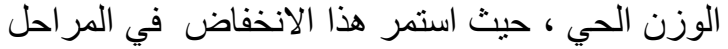

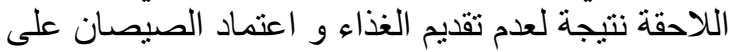

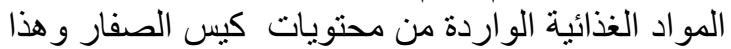

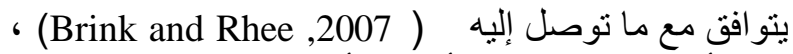

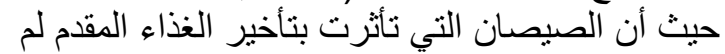

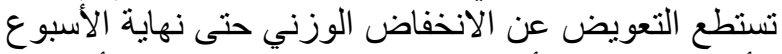

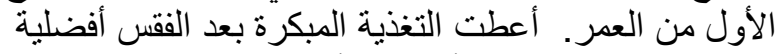
في الوزن الحي خلال الأسبوع الأول من العمر و وهذا يتفق العنق مoy and و مع (El-Husseiny et al., 2008)

.( Noy and Sklan, 2001)و(Sklan,1999a ) لوحظ عند التغذية المبكرة (بعد 6 ساعات من الفقس) في نهاية اليوم الأول بعد الفقس زيادة معنوية (P<0.05)

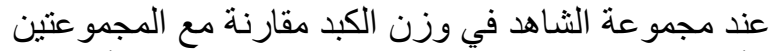

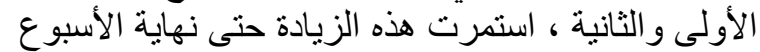

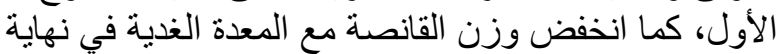

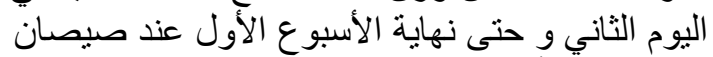

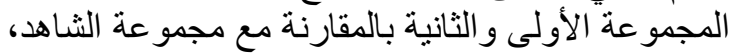
بينما لم يلاحظ أبي تأثير معنوي لتأخير تقديم العلف
جدول (2): محتوى الخلطات العلفية المستخدمـــة في تغذية الفراريج من المكونات الغذائيةالمختلفة

\begin{tabular}{|c|c|c|c|}
\hline الثرحلة & الثرحلة & الأولى & المكون الغذائي \\
\hline $42-36$ & $35-15$ & $14-1$ & \\
\hline 3031 & 2972 & 2867 & الطاقة الاستقلابية (ك. \\
\hline 16.3 & 18.1 & 21.2 & البروتين الخام(\%) \\
\hline 186 & 164.2 & 135.2 & ME/P \\
\hline 3.13 & 3.03 & 2.77 & دهن خام(\%) \\
\hline 2.88 & 3 & 3.35 & ألياف خام(\%) \\
\hline 0.9 & 0.94 & 0.96 & كالسيوم(\%) \\
\hline 0.73 & 0.74 & 0.77 & فوسفور كلي (\%) \\
\hline 0.91 & 1.00 & 1.27 & ليسين(\%) \\
\hline 0.41 & 0.42 & 0.47 & ميثيونين(\%) \\
\hline 0.33 & 0.35 & 0.41 & سستين(\%) \\
\hline 0.74 & 0.77 & 0.88 & مثيونين+سستين(\%) \\
\hline 1.40 & 1.35 & 1.32 & حمض اللينوليك(\%) \\
\hline
\end{tabular}

2.2. متوسط الوزن الحي

عن طريق وزن الجسم بشّكل إفرادي من عمر يوم وكل أسبو ع لكل المجمو عات التجريبية.

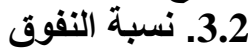

تم تدوين النافق _ المعزول صحياً وتحديد سبب النفوق أو الاستبعاد.

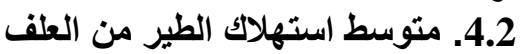

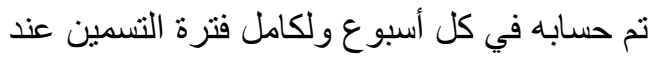

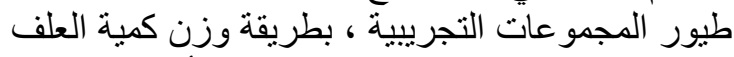

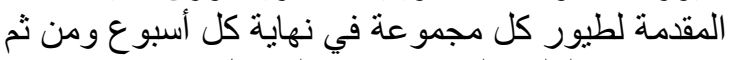

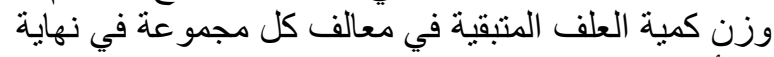
كل أسبوع وبعدها يتم حساب منوسط استهلية التهاك الطير الواحد من العلف بالعلاقة النالية: متوسط استهلاك الطير من العلف خلال المرحلة (جم) =

كمية العلف المستهلكة في كل مجموعة خلال المرحلة (جم)

متوسط عدد الطيور في كل مجموعة خلال المرحلة

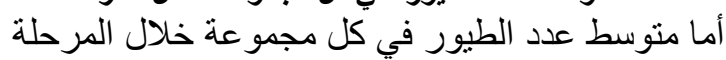
فيحسب على الثنل النتالي:

متوسط عدد الطيور في كل مجموعة خلال المرحلة (طيراً) =

نتائج جمع عدد الطيور في كل يوم من أيام المرحلة

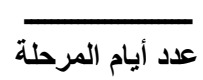

معامل التحويل الغذائي: نم حسابه لطيور كل مكرر في كل أسبو ع وفق المعادلة:

متوسط كمية العلف المستهلكة من قبل الطير (جم)

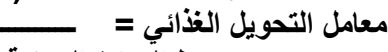

متوسط الزيادة الوزنية 5.2. تقييم الذبيحة

وذلك بأخذ 3 طيور من كل مجموعة قريبة من 
جدول رقم (3) الالايل الوزنية و الطولية في الأسبوع الأول

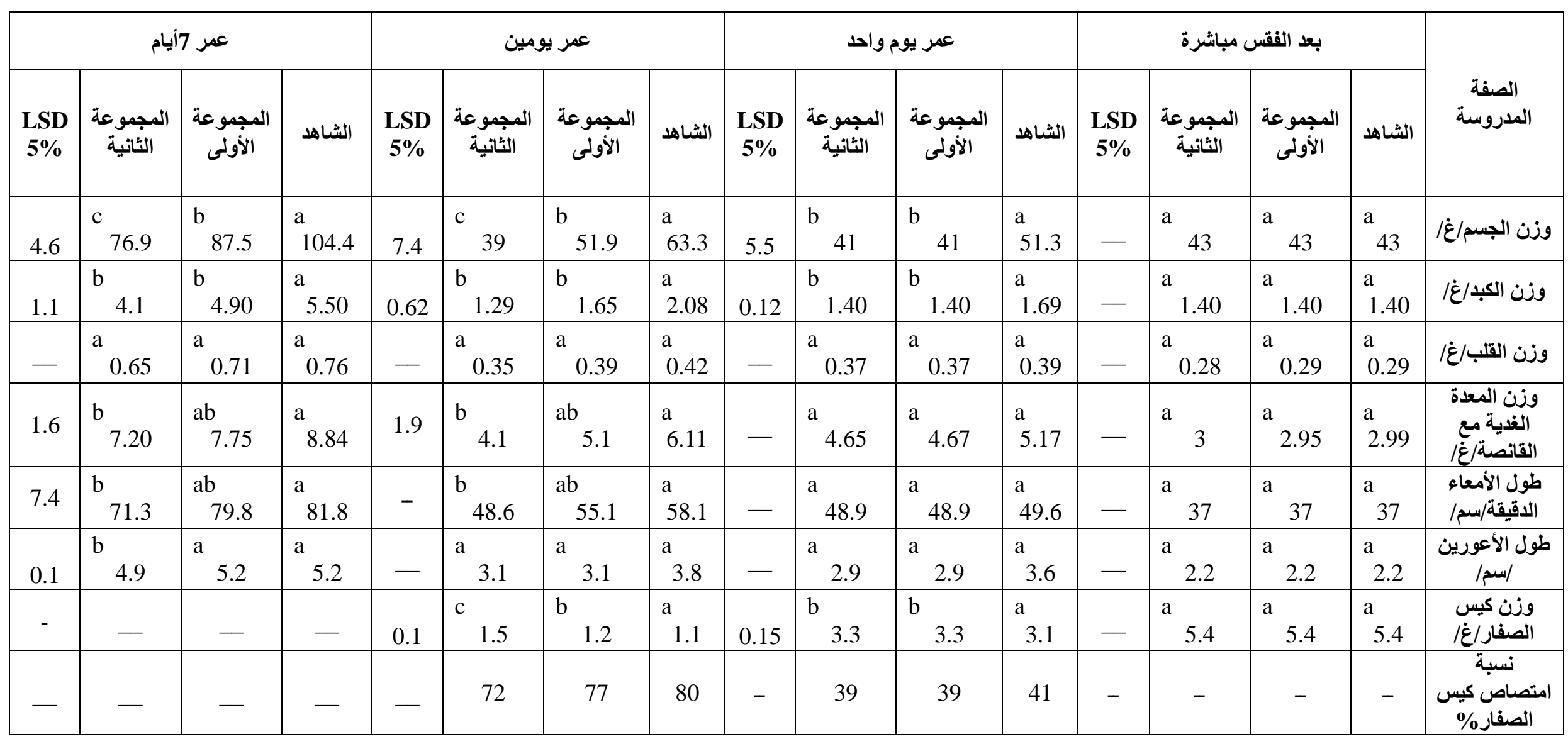


انعكس سلباً في مؤشر منوسط الوزن الحي مقارنة

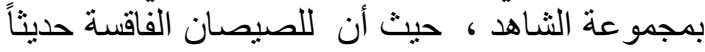

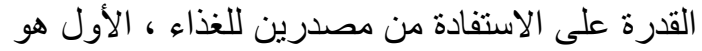

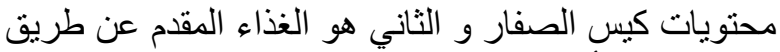

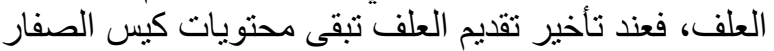

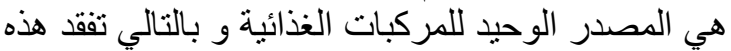

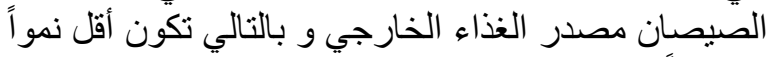

و حجماً مقارنة مع الصيصان المغذاة بشكل مبكر بالئ

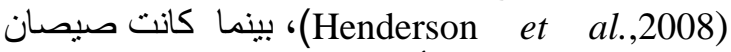

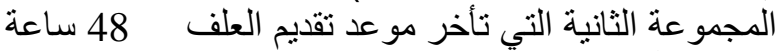

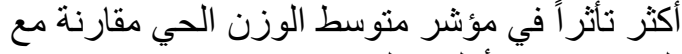
المجمو عتين الأولى و الثناهد.

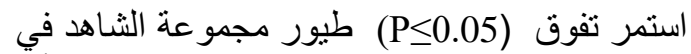
مؤشر متوسط الوزن الحي على طيور المجمو عتين الأولى لئى

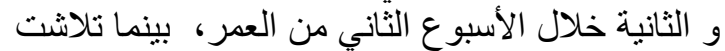

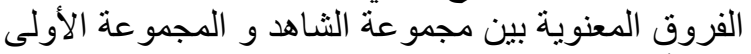

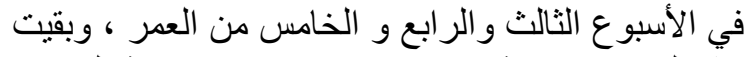
هذّه الفروق معنويةت ( P

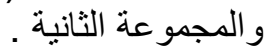

جدول (4): متوسط الوزن الحي الأسبوعي( جم) خلال مراحل

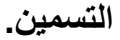

\begin{tabular}{|c|c|c|c|c|}
\hline \multirow{2}{*}{$\begin{array}{c}\text { L.S.D } \\
\% 5\end{array}$} & \multicolumn{3}{|c|}{ المجموعات التجريبية } & \multirow[b]{2}{*}{ العمر/يوم } \\
\hline & الثجموعة الثمانة & الأولىوعة & الثماهد & \\
\hline 4.6 & $\begin{array}{l}\text { c } 76.9 \\
\end{array}$ & $\begin{array}{l}\mathrm{b}_{87.5} \\
\end{array}$ & $\begin{array}{l}\mathrm{a} \\
104.4\end{array}$ & 7 \\
\hline 8.11 & $\begin{array}{l}\mathrm{b} \\
316.2\end{array}$ & $\begin{array}{l}\mathrm{b} \\
317.3\end{array}$ & $\begin{array}{l}\mathrm{a} \\
326.6\end{array}$ & 14 \\
\hline 16.5 & $\begin{array}{l}\mathrm{b} \\
608.2\end{array}$ & $\begin{array}{l}\mathrm{ab} \\
612.1\end{array}$ & $\begin{array}{l}\mathrm{a} \\
625.7\end{array}$ & 21 \\
\hline 42.2 & $\begin{array}{l}\mathrm{b} \\
1043.5\end{array}$ & $\begin{array}{l}\mathrm{ab} \\
1053.2\end{array}$ & $\begin{array}{l}\mathrm{a} \\
1093.1\end{array}$ & 28 \\
\hline 55.1 & $\begin{array}{l}\mathrm{b} \\
1550.7\end{array}$ & $\begin{array}{l}\mathrm{ab} \\
1563.1\end{array}$ & $\begin{array}{l}\mathrm{a} \\
1610.2\end{array}$ & 35 \\
\hline 65.3 & $\begin{array}{l}\mathrm{b} \\
2044.4\end{array}$ & $\begin{array}{l}\mathrm{a} \\
2111.4\end{array}$ & $\begin{array}{l}\mathrm{a} \\
2138.3\end{array}$ & 42 \\
\hline
\end{tabular}

ملاحظة :الأحرف المختلفة في نفس السطر تثل على وجود فروق معنوية على مستوى50

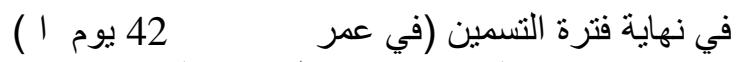

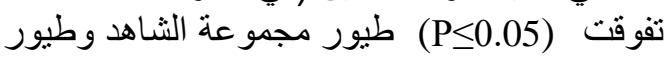

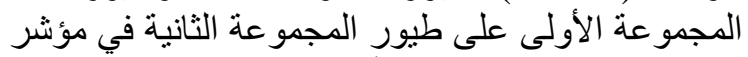

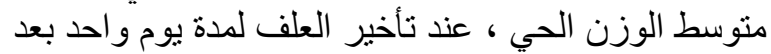

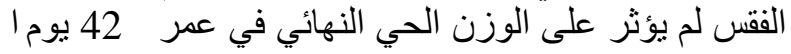

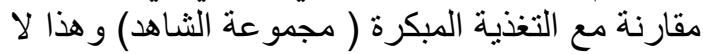
يتو افق مع ما توصل إليه ( El-Husseiny et al., 2008). بينما لوحظ عند تأخير تقديم العلف لمدة بو بومين بعد الفقس الفي قد أدى إلى انخفاض في منوسط الوزن الحي النهائي عند

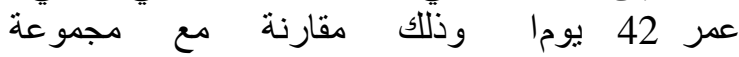

لمدة يوم أو يومين على وزن القلب و ذلك خلال الأسبوع

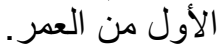

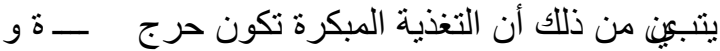

ضرورية لنمو و تطور الكبد و المعدة الغدية و القانصة الكية و و

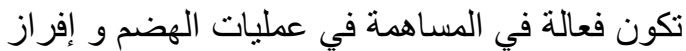

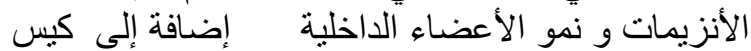

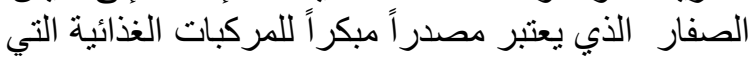
تساعد على النمو و التطور و ذللك يؤدي إلى اللى تحسين الآداء

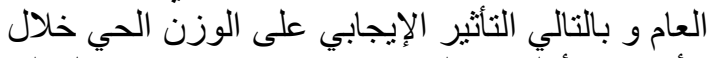

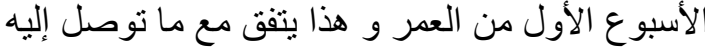
(Henderson et al.,2008)و (Noy and Sklan, 1998)

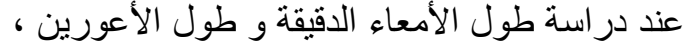
تثبير النتائج إلى زيادة معنوية (P الاقيقة عند صيصان مجمو عة الثشاهد مقارنة مع صيصان صيصان

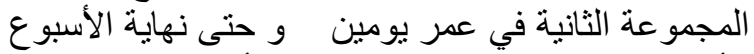

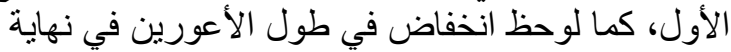

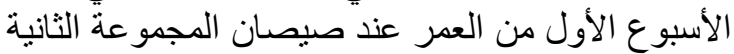

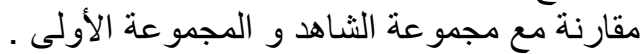

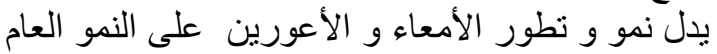

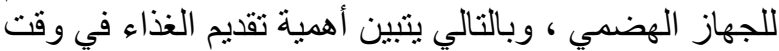

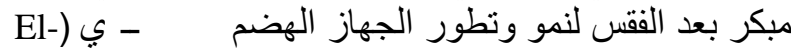

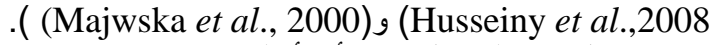
يستدل من الجدول (3) أن أعلى نسبة لامتصاص كيس (200)

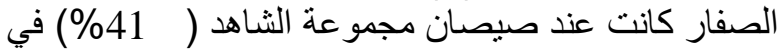

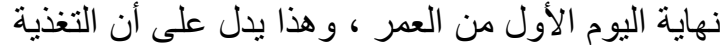

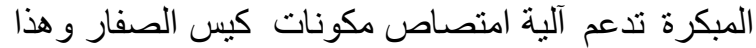
يتفق مع الباحثين (Noy and Sklan, 2001 )، وفي لثين نهاية

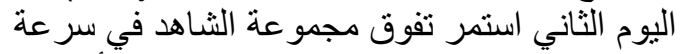

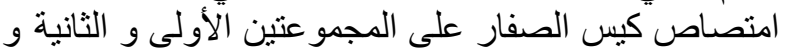

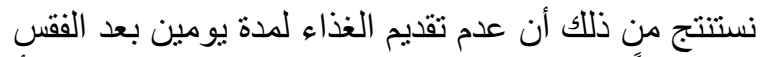

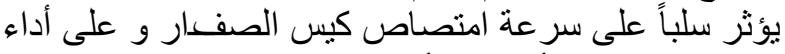

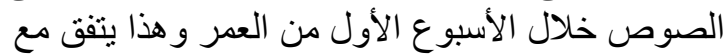

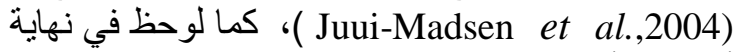

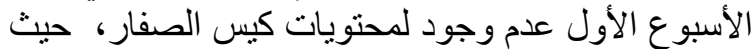

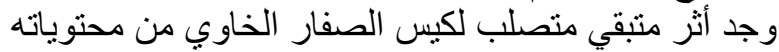
وذللك بسبب امنصاص كامل محتويات كيس الصفار خلار خلال

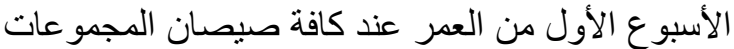

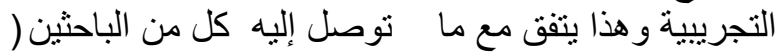

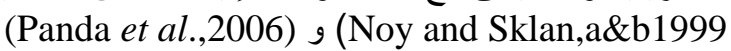
2.3. متوسط الوزن الحي يبين الجدول (4) منوسط الوزئ الوزن الحي( جم ) الأسبو عي

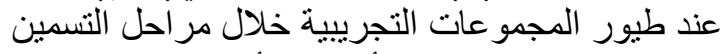

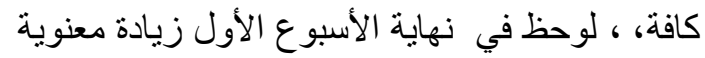

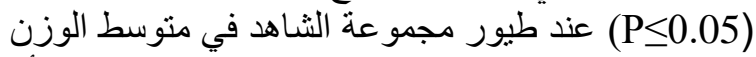

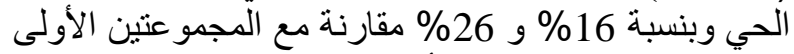

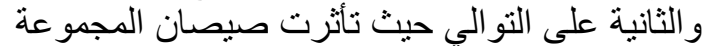
الأولى بتأخير مو عد تقديم العلف 24 ساعة مما لتران 
مستمرة في نسبة النفوق و ذللك في الأسبوع الأول من العمر

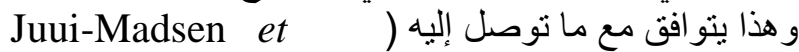

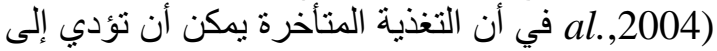

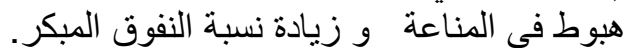

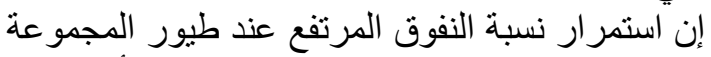

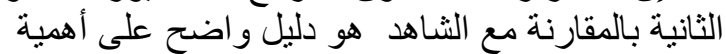

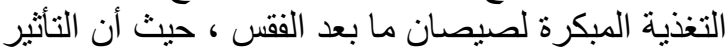

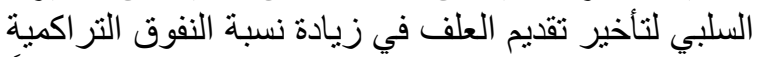

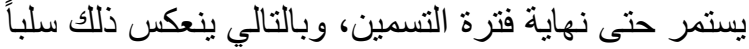

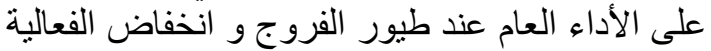

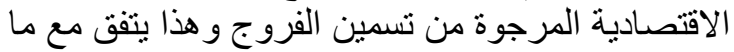
توصل إليه (Tweed,2005). 4.3.استهلاك العلف و الزيادة الوزنية و معامل التحويل

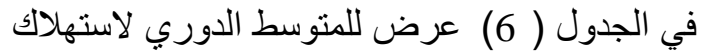

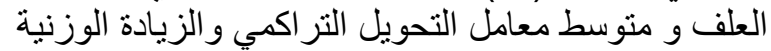

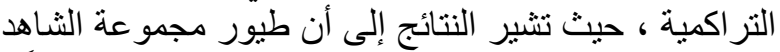

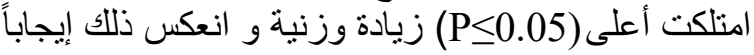

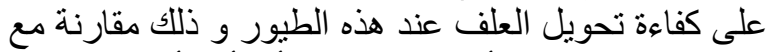

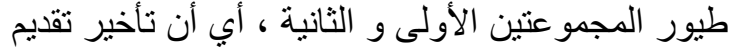

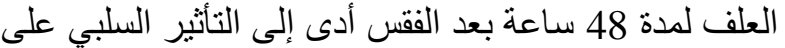

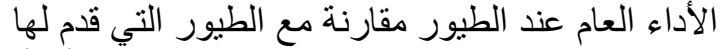

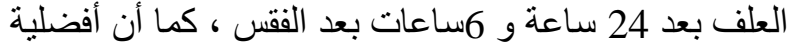

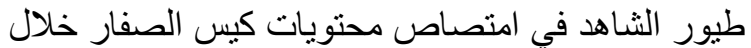

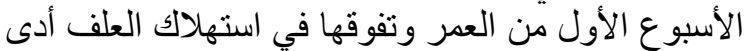

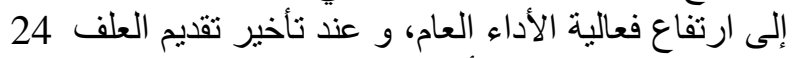

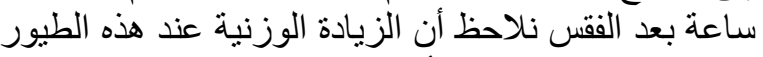

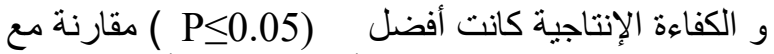

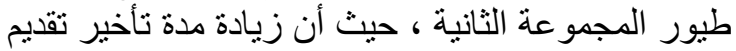

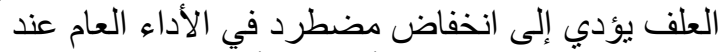

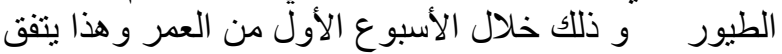

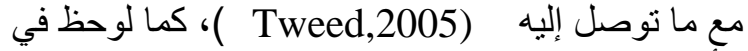

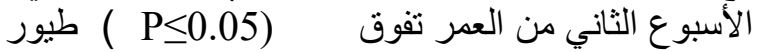
مجمو عة الثاهد في مؤشر الزيادة الوزنية الونية و كفاءة تحويل

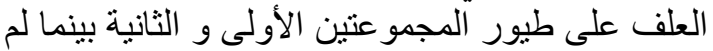

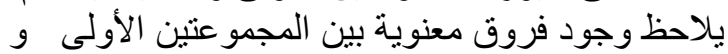

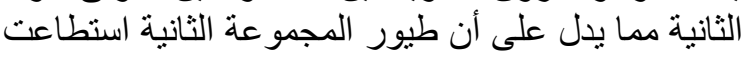

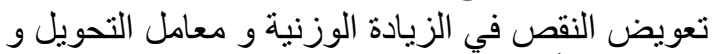

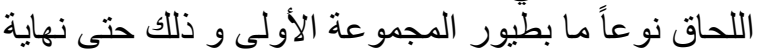

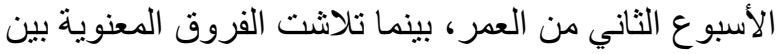

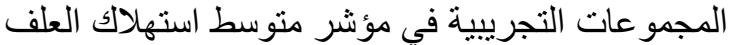
التر اكمي في الأسبوع الثالث من العمر ، كما فئر استمرت

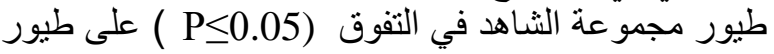
المجموعة الثانية في مؤشر الزيادة الوزنية و كفاءة تحويل العلف.

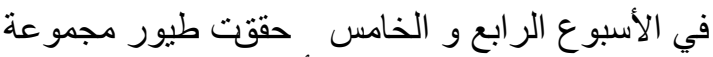
الثاهد زيادة وزنية و كفاءة غذائية الفضل الفئل

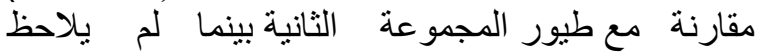

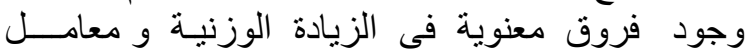

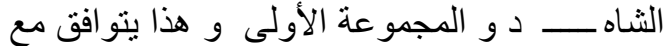
(Henderson et al.,2008)، كما لوحظ التشمر ارية

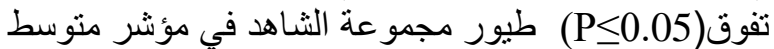
الوزن الحي على طبور المجمو عتين الأولى و الثنانية خلال

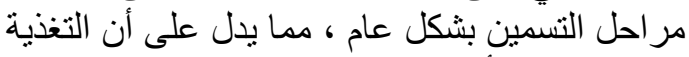

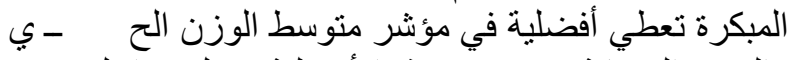

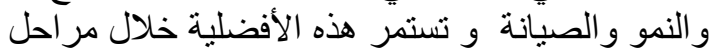

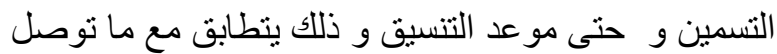
إليه كل من الباحثين (Noy and Sklan,1999b) ) (Halvy) .(Henderson et al., 2008) و et al., 2000) 3.3.نسبة النفوق يشير الجدول ( 5) إلى ارتفاع) عند طيور المجموعة الثانية و ذللك مقارنة مع طيور الثيور

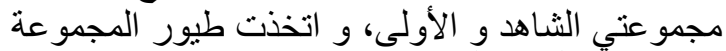

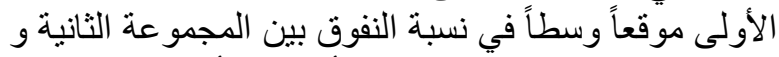

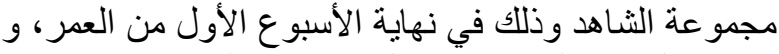

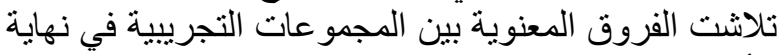

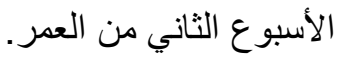

جدول (5): متوسط نسبة النفوق التراكمية \% خلال مراحل التسمين:

\begin{tabular}{|c|c|c|c|}
\hline \multicolumn{3}{|c|}{ المجموعات التجريبية } & \multirow{2}{*}{ العمر/يوم } \\
\hline المجموعة الثانية & المجموعة الأولى & مجموعة الثاهد & \\
\hline $\begin{array}{ll}\text { c } & \\
& \end{array}$ & b 2 & $\begin{array}{ll}\mathrm{a} & \\
& 1 \\
\end{array}$ & 7 \\
\hline a & $\begin{array}{l}\mathrm{a} \\
\end{array}$ & $\begin{array}{l}\mathrm{a} \\
\end{array}$ & 14 \\
\hline $\begin{array}{ll}\mathrm{b} & \\
& 4.3\end{array}$ & $\begin{array}{ll}\mathrm{ab} & \\
& 4\end{array}$ & $\begin{array}{ll}\mathrm{a} & \\
& 3.7\end{array}$ & 21 \\
\hline $\begin{array}{l}\mathrm{b} \\
\quad 5.7 \\
\end{array}$ & $\begin{array}{ll}a b & \\
& 5 \\
\end{array}$ & $\mathrm{a}$ & 28 \\
\hline $\mathrm{b}$ & $\begin{array}{ll}\mathrm{ab} & \\
& 6.3 \\
\end{array}$ & $\begin{array}{ll}\mathrm{a} & \\
& 5 \\
\end{array}$ & 35 \\
\hline $\begin{array}{l}\text { b } \\
\quad 7.3 \\
\end{array}$ & $\begin{array}{ll}a b & \\
& 7 \\
\end{array}$ & $\begin{array}{ll}\mathrm{a} & \\
& 6.7 \\
\end{array}$ & 42 \\
\hline
\end{tabular}

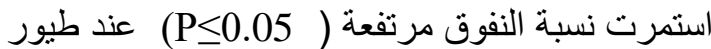

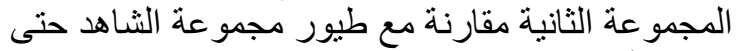
نهاية الأسبوع الثالث و حتى نهاية فترة التسمين، كما تبين

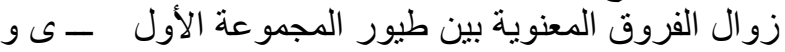
طيور المجمو عتين الثناهد و الثانية بعد الأسبوع الأول الأول من العمر وحتى التنسيق.

تنثير هذه النتائج إلى أن تأخير تقديم العلف لمدة 24

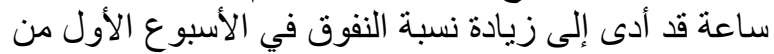

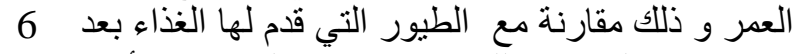

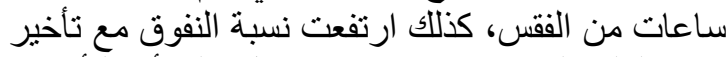

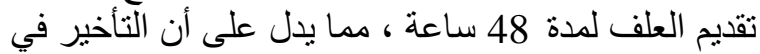
تقديم لعلف لأكثر من 6 ساعات بعد الفقس يؤدي إلى زيمادة التير فئ 


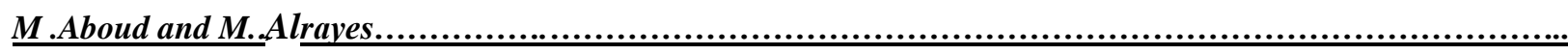

جدول(6): متوسط إستهلاك العلف التراكمى ومتوسط الزيادة الوزنية التراكمية ومعامل التحويل التراكمى.

\begin{tabular}{|c|c|c|c|c|c|}
\hline \multirow{2}{*}{$\begin{array}{l}\text { LSD } \\
5 \%\end{array}$} & \multicolumn{3}{|c|}{ المجموعات التجريبية } & \multirow{2}{*}{ الصفة المدروسة } & \multirow{2}{*}{ العمر/يوم } \\
\hline & الثانية & الأولى & الشـاهد & & \\
\hline 7.3 & $\begin{array}{ll}\mathrm{c} & \\
& 37.6\end{array}$ & $\begin{array}{ll}\mathrm{b} & \\
& 50.1\end{array}$ & $\begin{array}{ll}\text { a } & \\
& 68.3\end{array}$ & استهلاك العلف(جم) & \\
\hline 5.1 & $\begin{array}{ll}\text { c } & \\
& 32.9\end{array}$ & $\begin{array}{ll}\mathrm{b} & 44.5 \\
\end{array}$ & $\mathrm{a}$ & الزيادة الوزنية(جم) & 7 \\
\hline 0.095 & $\begin{array}{ll}\mathrm{c} & \\
& 1.143\end{array}$ & $\begin{array}{ll}\mathrm{b} & \\
& 1.125\end{array}$ & $\mathrm{a}$ & معامل التحويل & \\
\hline - & $\begin{array}{ll}\mathrm{a} & \\
& 412.8\end{array}$ & 413.2 & 410.1 & استهلاك العلف(جر) & \\
\hline 8.1 & $\begin{array}{ll}\mathrm{b} & \\
& 273.2\end{array}$ & 275.3 & $\mathrm{a}$ & الزيادة الوزنية(جم) & 14 \\
\hline 0.050 & $\begin{array}{ll}\mathrm{b} & \\
& 1.511\end{array}$ & 1.501 & $\mathrm{a}$ & معامل التحويل & \\
\hline - & $\begin{array}{ll}\mathrm{a} & \\
& 924.1\end{array}$ & $\begin{array}{l}\text { a } \\
\end{array}$ & $\begin{array}{l}\mathrm{a} \\
\end{array}$ & استهلاك العلف(جم) & \\
\hline 15.2 & $\begin{array}{ll}\mathrm{b} & \\
& 565.2\end{array}$ & $\begin{array}{ll}\text { ab } & \\
& 569.1\end{array}$ & $\mathrm{a}$ & الزيادة الوزنية(جم) & 21 \\
\hline 0.031 & $\begin{array}{ll}\mathrm{b} & \\
& 1.635\end{array}$ & $\mathrm{ab}$ & $\mathrm{a}$ & معامل التحويل & \\
\hline 65.7 & $\begin{array}{ll}\mathrm{b} & \\
& 1712.9\end{array}$ & $\begin{array}{ll}\text { ab } & \\
& 1721.4\end{array}$ & $\begin{array}{ll}\mathrm{a} & \\
& 1786.2\end{array}$ & استهلاك العلف(جم) & \\
\hline 35.2 & $\begin{array}{ll}\mathrm{b} & \\
& 1000.5\end{array}$ & $\begin{array}{ll}\mathrm{ab} & \\
& 1010.2\end{array}$ & 1050.1 & الزيادة الوزنية(جم) & 28 \\
\hline 0.010 & $\begin{array}{ll}\mathrm{b} & \\
& 1.712\end{array}$ & 1.704 & 1.701 & معامل التحويل & \\
\hline 55.5 & $\begin{array}{ll}\mathrm{b} & \\
& 2866.1\end{array}$ & 2880.6 & 2932.2 & استهلاك العلف(جم) & \\
\hline 45.3 & $\begin{array}{ll}\mathrm{b} & \\
& 1507.7\end{array}$ & 1520.1 & 1567.2 & الزيادة الوزنية(جم) & 35 \\
\hline 0.029 & $\begin{array}{ll}\mathrm{b} & \\
& 1.901\end{array}$ & 1.895 & 1.871 & معامل التحويل & \\
\hline 62.2 & $\begin{array}{ll}\mathrm{c} & \\
& 4004.8\end{array}$ & 4126.5 & 4069.1 & استهلاك العلف(جم) & \\
\hline 26.3 & $\begin{array}{ll}\text { c } & \\
& 2001.4\end{array}$ & 2068.4 & 2095.3 & الزيادة الوزنية(جم) & 42 \\
\hline 0.006 & $\begin{array}{ll}\mathrm{c} & \\
& 2.001\end{array}$ & 1.995 & 1.942 & معامل التحويل & \\
\hline
\end{tabular}


البطني في عمر 35 يوما وذللك مقارنة مع طيور الشاهد

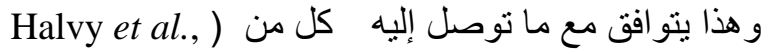
و (El-Husseiny et al., 2008) (2000 (Henderson et al.,2008)

جدول (7): تقييم مواصفات الذبيحة (\%من وزن قبل الذبح) في عمر35

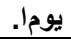

\begin{tabular}{|c|c|c|c|c|}
\hline \multicolumn{4}{|c|}{ المجموعات التجريبية } & \multirow[b]{2}{*}{ الصفة المدروسة } \\
\hline $\begin{array}{c}\text { L.S.D5 } \\
\%\end{array}$ & الثانية & الأولى & الثاهد & \\
\hline 2.1 & $\begin{array}{l}\mathrm{b} \\
75.2\end{array}$ & $\begin{array}{l}\mathrm{ab} \\
77.1\end{array}$ & $\begin{array}{l}\mathrm{a} \\
78.8\end{array}$ & الأحشيحة منزوعة الداخلية \\
\hline - & ${ }^{a} 74$ & $\begin{array}{l}\mathrm{a} \\
74.9\end{array}$ & ${ }^{\mathrm{a}} 77.5$ & نسبة التصافي \\
\hline- & $\mathrm{a}_{2.4}$ & $\mathrm{a}_{2.5}$ & a 2.6 & العضلية(القانصةة \\
\hline 0.3 & $\mathrm{~b}_{1.5}$ & $\mathrm{~b}_{1.5}$ & $\mathrm{a}_{1.2}$ & الدهن البطني \\
\hline 1.2 & $\begin{array}{l}\mathrm{b}_{13.3} \\
\end{array}$ & $\begin{array}{l}\mathrm{b} \\
13.7\end{array}$ & $\mathrm{a}_{15.1}$ & عضلات الصدر \\
\hline 1.3 & $\begin{array}{l}\mathrm{b}^{6} \\
6.7\end{array}$ & $\begin{array}{l}\mathrm{ab} \\
7.7\end{array}$ & $\begin{array}{l}\mathrm{a}_{7.8} \\
\end{array}$ & عضلات الفذذ \\
\hline - & $\begin{array}{l}\mathrm{a} \\
6.6\end{array}$ & a 6.8 & a 6.9 & عضلات تحت \\
\hline
\end{tabular}

جدول (8): تقييم مواصفات الذبيحة (\%من وزن قبل الذبح) في

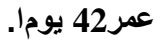

\begin{tabular}{|c|c|c|c|c|}
\hline \multicolumn{4}{|c|}{ المجموعات التجريبية } & \multirow[b]{2}{*}{ الصفة المدروسة } \\
\hline $\begin{array}{r}\text { L.S.D } \\
\mathbf{5 \%}\end{array}$ & الثانية & الأولى & الشاهد & \\
\hline 1.1 & $\begin{array}{l}\mathrm{b} \\
78\end{array}$ & $\begin{array}{l}\mathrm{ab} \\
78\end{array}$ & $\begin{array}{l}\mathrm{a} \\
79\end{array}$ & 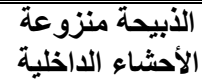 \\
\hline- & $\stackrel{\mathrm{a}}{76.5}$ & ${ }^{a} 76.6$ & $\stackrel{\mathrm{a}}{76.7}$ & نسبة التصافي \\
\hline - & ${ }^{\mathrm{a}} 2.3$ & a 2.2 & ${ }^{\mathrm{a}} 2.5$ & العضلية(القانصة) \\
\hline 0.2 & $\mathrm{~b}_{1.6}$ & $\begin{array}{l}\mathrm{ab} \\
1.6\end{array}$ & $\mathrm{a}_{1.4}$ & الد هن البطني \\
\hline 0.3 & $\begin{array}{l}\mathrm{b}_{15.2} \\
\end{array}$ & $\begin{array}{l}\mathrm{ab} \\
15.6\end{array}$ & $a_{16}$ & عضلات الصدر \\
\hline 0.6 & $\mathrm{~b}_{7.5}$ & $\begin{array}{l}\mathrm{ab} \\
7.9\end{array}$ & ${ }^{2} 8$ & عضلات الفخذ \\
\hline - & $\mathrm{a}_{7.3}$ & a 7.3 & ${ }^{\mathrm{a}} 7.3$ & عضلات تحت \\
\hline
\end{tabular}

2.5.3.مواصفات الأبيحة في عمر 42 يوما

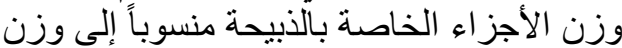
الجسم للطيور قبل الذبح في عمر

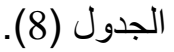

التحويل بين المجمو عتين الأولى و الثانية و بين مجموعة

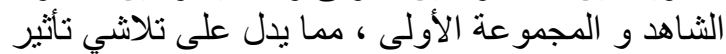

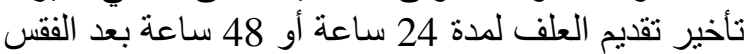

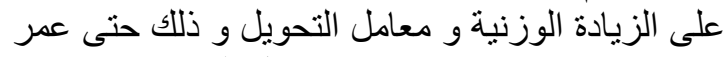
35 يوم و هذا لا يتو افق مع ما نوصل معل إليه (Henderson) et al.,2008)

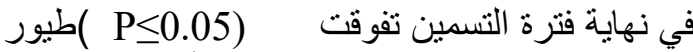

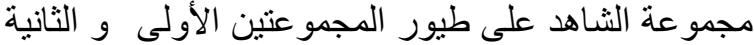

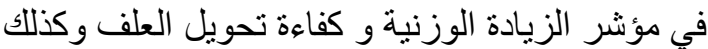
تفوقت (P<0.05 ) طيور المجموعة الأولى على طيور

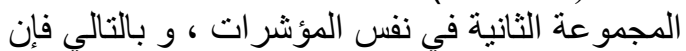

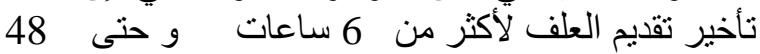

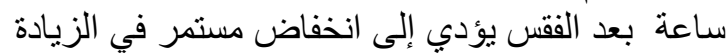
الوزنية و الكفاءة الإنتاجية ، حيث العيث أن التغذية المبكرة

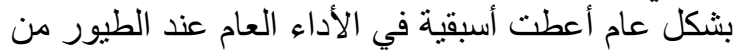

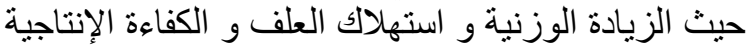

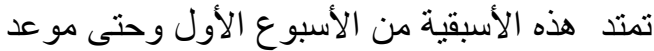
التنسيق و هذا يتطابق مع(Henderson et al.,2008 ) و و ) .El-Husseiny et al., 2008) 5.3.3. مواصفات الأبيحة

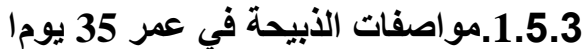

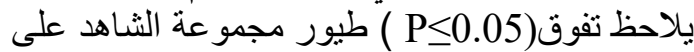

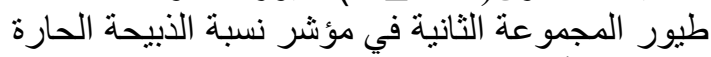

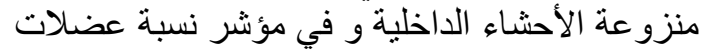

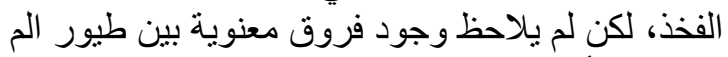

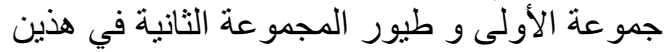

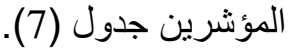

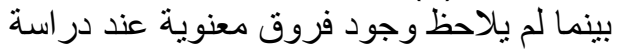
مؤشر نسبة التصافي و مؤشر المعدة العضلية (القانصة) و مؤشر عضدات تحت الفخذ بين طيور المجمو عات التجريبية كافة. تفوقت (P<0.05) طيور مجمو عة الشاهد على طيور

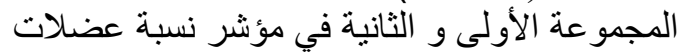

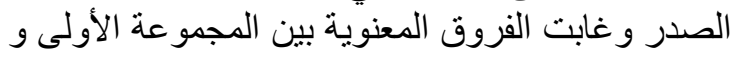

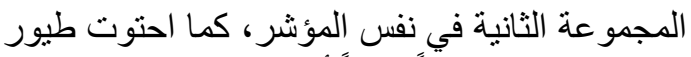

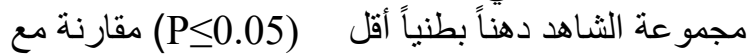

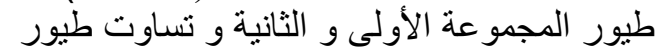
المجمو عتين الأولـى و الثانية في نسبة الدهن البطني.

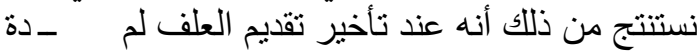

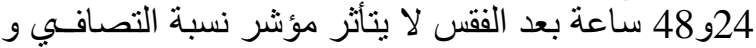

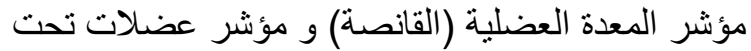
الفخذ في عمر 35 يوما. لكن أدى تأخير تقديم العلف لمدة

الفقس إلى انخفاض في مؤشر نسبة عضلاخت أنسات الفخذ و

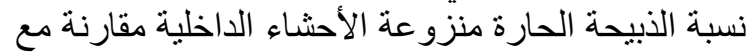

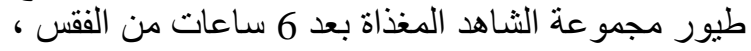

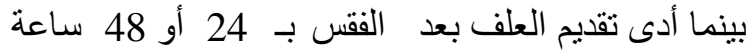

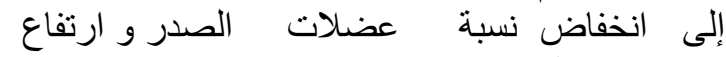

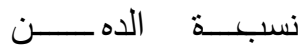




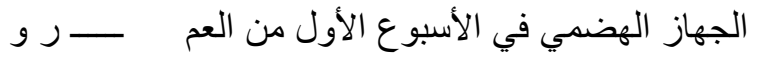

$$
\begin{aligned}
& \text { المؤشر ات الإنتاجية في عمر التنسيق. }
\end{aligned}
$$

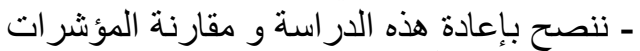

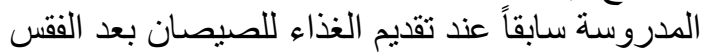

$$
\begin{aligned}
& \text { مباشرة مع صبصان قدم لها الغذاء بعد فتر ات متعددة من لفن }
\end{aligned}
$$

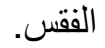

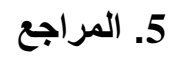

$$
\begin{aligned}
& \text { المراجع العربية }
\end{aligned}
$$

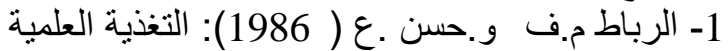

$$
\begin{aligned}
& \text { اللدراجع الأجنية العزية العلي) ، منشور ات جامعة دمثق. }
\end{aligned}
$$

Anthony N.B., Dunington E.A. and Siegl P.B. (1989).Embryo growth of normal and dwarf chickens from lines selected for high and low 50-day body weight .Arch. Geflugelkd, 53:116-122.

Batal,A.B.and Parson C.M. (2002).Effect of asting versus feeding oasis after hatching on nutrition utilization in hicks.Poult.Sci.,81:853-859.

Brink M.V.D. and Rhee W.V.( 2007).Semimoist diets to improve day old chicks performance.World Poult.Sci. 63:17-19.

El-Husseiny, O.M., Abou El-Wafa S. and ElKomy H.M.A. (2008). Influence of fasting or early feeding on broiler performance. Inter.J.Poult.Sci.73 (3):263-271.

Esteban S., Royo J. , Moreno M. , Sastre M., Rial R. and Tu J. (1991). A role played by the vitalized diverticulum's in the yolk sac sac absorption in young posthatched chickens . J. Comp. Physiol .B, 160:645648.

Grela B. Tos(1998). Polskie Drob. 8, 31-32 34Gillat A., 1992. Zgodnie Z Z aieceniami stosowanymi W Krajack EOW. Drobiarstw, 2:32-34.

Halevy O.A., Barak M., Uni Z. and Sklan D. (2000). Early post hatch starvation decreases satellite cell proliferation and muscle growth in the chick. J.Nutr.130:858-864.

Henderson, S.N., Vicent J.L., Pixly C.M., Hargis B.M. and Tellez G. (2008). Effect of an early nutrition supplement on broiler performance Inter.J.Poult.Sci.73(3):211-214.

Jamroz, D. and Wertelecki T. (1998). Miedzynarodowe sympozjum drobiarskie WPSA ,cz.II ,133-135. Olsztyn- Poland.

Juui-Madsen Su H.R.,G. and Sarensen P.( 2004). Influence of early or late start of first feeding on growth and immune phonotype of broiler. Br.Poult.Sci.,45:210-222.

Majewski T., Zankowski J. and Siwik T.(2000). wptyw zastosownia roznych mieszanek
التجريبية في مؤشر نسبة التصافي ودو معنو مؤشر نسبة المجمو المعدة

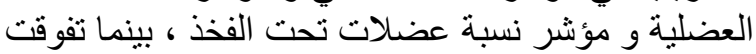

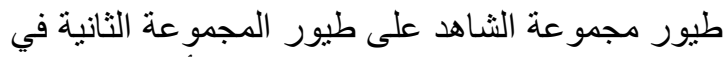

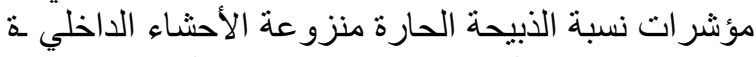

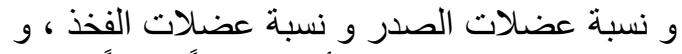

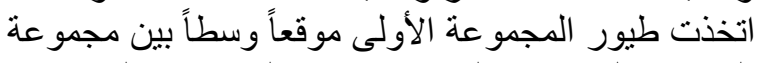
الثاهد و المجمو عة الثانية من حيث الاولى المؤشر الثرات السابقة .

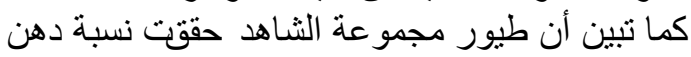

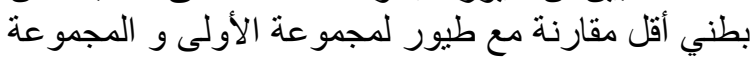
الثانية

تثشير هذه النتائج في عمر التسويق (42 يوما) إلى أن

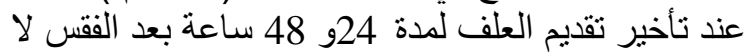
يؤثر على مؤشر نسبة التصافي و مؤشر المعان المعدة العضلية

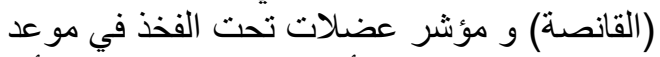

التنسيق، مما يدل على أن طئن طيور المجمو عتين الأولى و

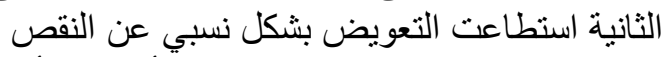

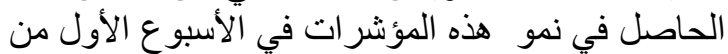
العمر في نهاية فترة التسمين.

لكن تقديم العلف بعد 48 ساعة من التبرة الفقس أدى إلى

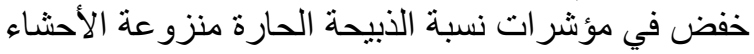

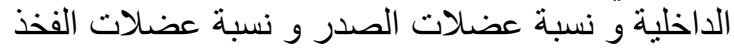

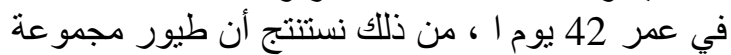

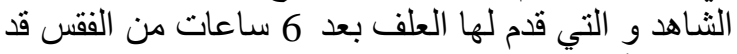

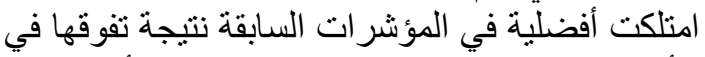

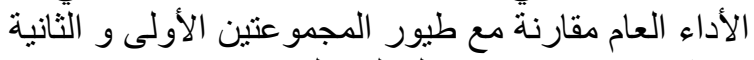

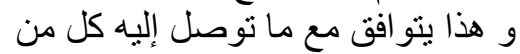

(Halvy et al.,2000)ون (Noy and Sklan,1999b) .(El-Husseiny et al.,2008)

$$
\begin{aligned}
& \text { 4. الإستنتاجات و التوصيات }
\end{aligned}
$$

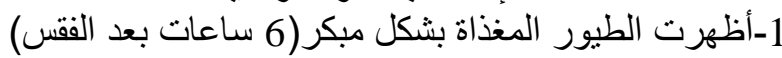

$$
\begin{aligned}
& \text { أفضلية في امتصاص كيس الصفارو تطور الجهاز }
\end{aligned}
$$

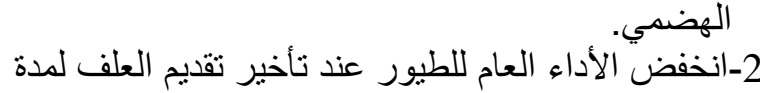

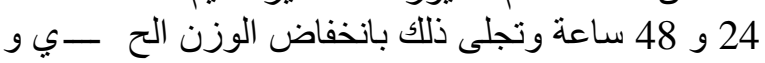

$$
\begin{aligned}
& \text { الكفاءة الإنتاجية و زيادة ونجئ نسب النفوق. }
\end{aligned}
$$

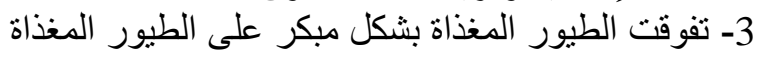

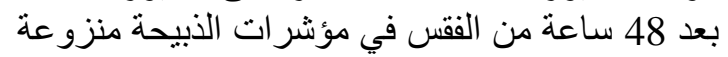

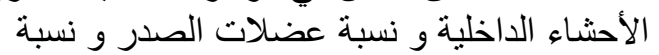

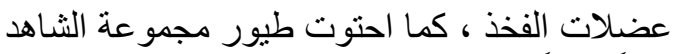

$$
\begin{aligned}
& \text { دهناً بطنياً أقل من طيور المجمو عتئن الفين الأولى و الثانية. }
\end{aligned}
$$

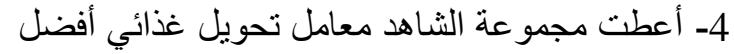

$$
\begin{aligned}
& \text { ون باقِي المجاميع خاصة في نهاية فترة التسمين. } \\
& \text { و بناءاً على ذلك نوصي بما يلّي: }
\end{aligned}
$$

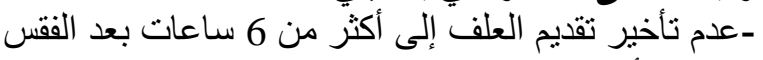

$$
\begin{aligned}
& \text { بسبب التأثير السلبي على امتصاص كيس الصفار وتطور }
\end{aligned}
$$


prestarte $r$ na rozwoj uktad pokarmoweg o ,resorpcje worczka zottkowego I wyniki odchowu indorow.zeszyty naukowe (49)-S 333-341.

Nitsan Z.,G.Ben-Avraham Z.Zorf and Nir I.(1991).Growth and development of the digestive organs and some enzymes in the broiler chick after hatching Br. Poultry Sci.,32:515-523.

Noy Y. and Sklan D. (1998). Yolk utilization of yolk in the newly hatched chicks. Br. Poult. Sci.39:987-995.

Noy Y. and Sklan D. (1999a). Effect of different types of early feeding on performance in chicks and poults. J.Appl. Poult. Res, 8:1624.

Noy Y. and Sklan D. (1999b). Energy utilization newly hatched chicks Poultry Sci., 78:17501756.

Noy Y. and Sklan D. (2001). Yolk and exogenous feed utilization in the posthatched chick. Poultry Sci.,80:14901495.

Panda A.K., Shyam Sunder G., Rama Rao S.V. and Raju M.V.L.N. (2006). Early nutrition enhances growth and speed up gut development. World Poult. Sci. 62:15-16. SPSS 13 for Windows, 2004. http: WWW.SPSS. COM.

Taxton J.P. and Parkhursl C.R.(1976). Growth efficiency and livability of newly hatched broiler as influenced by ration and intake of sucrose. Poultry Sci., 55:2275-2279.

Tweed S.(2005). The heth winow. CobbVantress technical focus. Vol.2.Siloam Springs, AR.

Wertlecki T.(2006).The changes of yolk sac composition in chicken fed pre-starter mixtures composed according to different nutrition recommendations. Vol.Electronic. J. Polish Agric. Univ.

Wertelecki T. and Jamroz D. (2000). Wptyw poziomu tuszczu w mieszance I czas rozpocze cia pierwscego karmienia na tempo resorpcji woreczka zottkowego zmiany aktywnosci enzymatycznej W trzustce I rozwoj prewodu pokarmowego $\mathrm{u}$ kurczat Zes. Nam-94 Chow. Drob. S. .387398.Poland. 
